\title{
Anterior Chest Wall Pain in Recent Inflammatory Back Pain Suggestive of Spondyloarthritis. Data from the DESIR Cohort
}

\author{
Daniel Wendling, Clément Prati, Christophe Demattei, Damien Loeuille, Pascal Richette, \\ and Maxime Dougados
}

\begin{abstract}
Objective. To determine the prevalence of anterior chest wall (ACW) pain in patients with recent inflammatory back pain (IBP) suggestive of spondyloarthritis (SpA), and to investigate the influence of ACW pain on the overall features of these patients.

Methods. The DESIR cohort is a prospective, multicenter French cohort of patients with early IBP suggestive of SpA, including 708 patients (mean age $33.8 \mathrm{yrs}, 53.8 \%$ females, 57.3\% HLA-B27-positive). ACW pain was defined by at least 1 episode of chest wall pain attributed to SpA by the rheumatologist, after ruling out other causes of chest pain. Data on the baseline demographic characteristics, functional status and quality of life, imaging features, bone mineral density, and blood tests were compared in patients with and those without ACW pain. Factors associated with ACW pain were identified by univariate and multivariate analysis (logistic regression).

Results. The prevalence of ACW pain in the DESIR cohort $(n=316 / 708$ patients) was $44.6 \%(95 \%$ CI 40.9-48.3). ACW pain occurred after the first symptoms of IBP in $62 \%$. Localization was diffuse in $41 \%$ of the positive cases. A stepwise multivariate analysis found an association between ACW pain and the enthesitis score, involvement of thoracic spine, diagnosis of ankylosing spondylitis (AS), and radiographic abnormalities of sacroiliac joints.

Conclusion. In recent IBP suggestive of SpA, presence of ACW pain is associated with enthesitis, thoracic spine involvement, radiographic sacroiliitis, diagnosis of AS, and with a more severe disease. ACW pain could be interpreted as a diagnostic feature for AS. (First Release May 15 2013; J Rheumatol 2013;40:1148-52; doi:10.3899/jrheum.121460)
\end{abstract}

Key Indexing Terms: ANTERIOR CHEST WALL STERNOCOSTAL JOINT

\section{MANUBRIOSTERNAL} SPONDYLOARTHRITIS
STERNOCLAVICULAR JOINT INFLAMMATORY BACK PAIN
Anterior chest wall (ACW) involvement is a classic feature in defined and advanced spondyloarthritis ( $\mathrm{SpA})$, but it is not included in classification or diagnostic criteria ${ }^{1}$. In a

From the Department of Rheumatology, University Hospital J. Minjoz, Besançon, France.

The DESIR study is conducted as a Programme Hospitalier de Recherche Clinique with Assistance Publique-Hôpitaux de Paris as the sponsor; and is supported by the French Society of Rheumatology and by an unrestricted grant from Pfizer France.

D. Wendling, MD, PhD, Professor of Rheumatology, Rhumatologie, $C H U$ de Besançon, and EA 4266, Université de Franche-Comté; C. Prati, MD, Maitre de Conférences en Rhumatologie, Rhumatologie, $\mathrm{CHU}$ de Besançon, and Université de Franche-Comté, Besançon; C. Demattei, PhD, Biostatistician, Department of Biostatistics, Epidemiology, Public Health and Medical Information, University Hospital, Nîmes; D. Loeuille, MD, Professor, Department of Rheumatology, University Hospital, Nancy; P. Richette, $M D, P h D$, Professor of Rheumatology, AP-HP Hôpital Lariboisière, Pôle appareil locomoteur, Fédération de Rhumatologie, Université Paris Diderot, Sorbonne Paris Cité, Paris; M. Dougados, MD, Professor of Rheumatology, Faculty of Medicine, Paris-Descartes University; Rheumatology Department B, AP-HP, Cochin Hospital, Paris, France.

Address correspondence to Prof. D. Wendling, Rheumatology, University Hospital J. Minjoz, Boulevard Fleming, Besançon 25030, France.

E-mail:dwendling@chu-besancon.fr

Accepted for publication March 14, 2013. series describing a population with established ankylosing spondylitis (AS; 50 patients fulfilling the Amor criteria, mean disease duration $12 \mathrm{yrs}$ ), Fournié, et $a l^{2}$ found a prevalence of ACW (sternocostoclavicular) involvement of 58\% by clinical examination and $50 \%$ by bone scintigraphy. Using radiographic material from a 10 -year retrospective study of 268 patients with seronegative arthritis, Jurik ${ }^{3}$ found changes in sternoclavicular joints in $17 \%$ of patients with AS, and in manubriosternal joints in $51 \%$ of patients with AS. In AS, the presence of ACW involvement was significantly related with duration of the disease, advanced sacroiliitis, and involvement of the spine and root joints. In a retrospective single-center study of 275 patients with established SpA, ACW pain was reported in $37.1 \%^{4}$, in relation with duration of disease.

Little is known about ACW involvement in early SpA or inflammatory back pain (IBP) suggestive of SpA and the patients' characteristics associated with this condition. The main objective of our study was to determine the prevalence of ACW pain and its characteristics in patients with recent IBP. The secondary objectives were to evaluate the influence of ACW pain on clinical, laboratory, and imaging 
findings [standard radiographs, magnetic resonance imaging (MRI) of the entire spine, ultrasound], bone mineral density (BMD), and body composition features (fat mass, lean mass), and fulfillment of classification criteria.

\section{MATERIALS AND METHODS}

This was a cross-sectional study evaluating all patients enrolled in the DESIR cohort and for whom data were available at baseline. The DESIR cohort is a prospective, multicenter French cohort of patients with early IBP (classified according to Calin ${ }^{5}$ or Berlin ${ }^{6}$ criteria, taking into account for the latter 2 out of 4 items) of more than 3 months' and less than 3 years' duration, with symptoms suggestive of SpA according to the local investigator's assessment (score $\geq 5$ on a 0 to 10 numerical rating scale in which $0=$ not suggestive and $10=$ very suggestive of SpA), and planned to be followed up for least 5 years. The method of assembly of the cohort and the main characteristics of patients at baseline have been reported ${ }^{7}$. This cohort included 708 patients: mean age 33.8 years, 53.8\% women, 57.3\% HLA-B27-positive. Presence or history of ACW pain was assessed by the investigators for all patients at baseline, and recorded by interview. ACW pain was defined by at least 1 episode of at least 1 day duration of inflammatory chest wall pain, as spontaneous symptoms, attributed to SpA by the rheumatologist, after other causes of chest pain were ruled out. The baseline characteristics included age, ethnicity, date at onset of IBP and peripheral arthritis, nature of IBP, presence of SpA features, relevant family history, and medication including use of nonsteroidal antiinflammatory drugs and disease-modifying antirheumatic drugs. Duration of axial symptoms was defined as the time between the first axial symptom and the initial interview. Examination was also performed to determine the Ritchie Articular Index (53 joints) and swollen joint count (28 joints), spinal mobility as measured by the Bath Ankylosing Spondylitis Metrology Index (BASMI) and chest expansion, and enthesitis index (Maastricht AS Enthesitis Score). Extraarticular features were also evaluated, particularly uveitis, psoriasis, and inflammatory bowel disease (IBD; presence or history with medical diagnosis).

Patients were asked to complete the Bath Ankylosing Spondylitis Disease Activity Index (BASDAI), the Bath Ankylosing Spondylitis Functional Index (BASFI), Bath Ankylosing Spondylitis Global index (BAS-G), Health Assessment Questionnaire (HAQ), Medical Outcomes Study Short Form-36 (SF-36), and AS Quality of Life score questionnaires.

Blood tests were performed in the regional rheumatology centers. These included C-reactive protein (CRP), erythrocyte sedimentation rate, and HLA-B27 antigen, and the usual biological measures. The Ankylosing Spondylitis Disease Activity Score (ASDAS) ${ }^{8}$ was calculated using CRP (ASDAS-CRP).

All imaging modalities (radiographs and MRI) were evaluated by the local radiologist or rheumatologist. Radiographs of the sacroiliac (SI) and hip joints were graded according to the following scale: $0=$ normal, $1=$ doubtful (grade 1), 2 = obvious (grade 2 or 3 ), and 3 = fusion. Lateral radiographs of the cervical and lumbar spine were used to calculate the modified Stoke AS Spine Score (mSASSS) ${ }^{9}$.

T1-weighted fast spin-echo (T1-FSE) and short-tau inversion recovery (STIR) 1-1.5 Tesla MRI of the spine and the SI joints were performed to assess inflammatory and structural lesions. The MRI scans were classified by the local radiologist or rheumatologist as having definite, doubtful, or absent inflammatory or structural lesions at the spinal and sacroiliac level.

Data on baseline demographic characteristics, functional status and quality of life, imaging features (standard radiographs, MRI, ultrasound), BMD, and blood tests were compared in patients with and those without ACW pain. These data allowed determination of European Spondylarthropathy Study Group (ESSG) score, Amor criteria, and Assessment of Spondyloarthritis International Society (ASAS) classification criteria ${ }^{1}$ for each patient. Both the date of the first symptom of IBP and the symptoms of ACW pain were recorded, as well as the date of the visit. Factors associated with the presence of ACW pain were identified by both univariate and then multivariate analysis (logistic regression with the variables significant in univariate analysis); $\mathrm{p}$ values $<0.05$ were considered significant. Data were extracted from the DESIR database locked at December 12, 2011.

Our study was approved by the French Departmental Directorate of Health and Social Affairs (Directeur Départemental des Affaires Sanitaires et Sociales) and received approval from the ethics committees. It was conducted in accord with the Declaration of Helsinki and the guidance for good clinical practice. All participants gave written informed consent to enter the study.

\section{RESULTS}

Prevalence. Three hundred sixteen cases of ACW pain were reported at baseline: the prevalence of $\mathrm{ACW}$ pain in the DESIR cohort $(n=316 / 708$ patients) was $44.6 \%$ (95\% CI 40.9-48.3). ACW pain occurred after the first symptoms of IBP in $62 \%$, before appearance of symptoms in $14 \%$, and simultaneously ( \pm 1 month) in $24 \%$ of cases. Localization was diffuse in $41 \%$ of the positive cases, sternocostal in $35 \%$, manubriosternal in $29 \%$, or sternoclavicular in $26 \%$, with the possibility of several simultaneous localizations.

Univariate analysis. Presence of ACW pain was significantly associated in univariate analysis (Table 1) with pain in cervical and thoracic spine, buttock, peripheral arthritis and enthesitis, fulfillment of ASAS modified New York criteria and ESSG criteria, associated reactive arthritis and SAPHO (synovitis, acne, pustolosis, hyperostosis, osteitis) syndrome, increased BASDAI, ASDAS, BASFI, BASG, BASMI and articular index, increased CRP, reduced SF-36 (physical and mental components), radiographic SI involvement, and reduced BMD (data not shown for BMD). ACW pain was not associated with body mass index, HLA-B27, chest expansion, dactylitis, uveitis, psoriasis, smoking, age, age at onset, or ultrasound and MRI findings (inflammatory or chronic changes, SI and spine; data not shown).

Multivariate analysis. A stepwise multivariate analysis found a statistically significant association between ACW pain and the enthesitis score, involvement of the thoracic spine, and radiographic abnormality of the SI joints (Table 2). Because of the relation between the 2 variables "diagnosis of AS" and "radiographic sacroiliitis," the former was deleted from the multivariate analysis (Table 2).

\section{DISCUSSION}

In this prospective cohort of patients with IBP suggestive of early SpA, ACW pain was found with a prevalence of $44.6 \%$. This is in the range of previous studies in established SpA and with smaller sample sizes. Among 45 patients with definite AS with a mean disease duration $>10$ years, Dawes, et $a l^{10}$ found chest pain in $63 \%$ of patients (and $7 \%$ of controls matched for sex and age). In a retrospective single-center cohort of established $\mathrm{SpA}^{4}$ at Cochin Hospital, Paris, ACW pain was reported in $37.1 \%$ of 275 patients, with a mean disease duration of 16 years. In 110 patients

Personal non-commercial use only. The Journal of Rheumatology Copyright $\odot$ 2013. All rights reserved. 
Table 1. Comparison of baseline characteristics between patients with and those without anterior chest wall $(\mathrm{ACW})$ pain (univariate analysis).

\begin{tabular}{|c|c|c|c|}
\hline Characteristics & $\begin{array}{l}\text { Patients with ACW, } \\
\qquad \mathrm{n}=316\end{array}$ & $\begin{array}{l}\text { Patients Without ACW, } \\
\qquad \mathrm{n}=392\end{array}$ & $\mathrm{p}$ \\
\hline Male sex, $\%$ & 45 & 47 & 0.6 \\
\hline Mean age, yrs & $33.6 \pm 8.5$ & $33.8 \pm 8.7$ & 0.8 \\
\hline \multicolumn{4}{|l|}{ Location of axial involvement since beginning } \\
\hline Cervical spine, $\%$ & 45 & 33 & 0.001 \\
\hline Thoracic spine, $\%$ & 67 & 49 & 0.000001 \\
\hline Gluteal, \% & 78 & 72 & 0.048 \\
\hline Peripheral articular involvement, $\%$ & 63 & 52 & 0.003 \\
\hline Entheses involvement, \% & 54 & 45 & 0.009 \\
\hline Diagnosis of ankylosing spondylitis at inclusion, $\%$ & 47 & 38 & 0.009 \\
\hline ASAS criteria fulfillment at inclusion, $\%$ & 72 & 65 & 0.04 \\
\hline ESSG criteria fulfillment at inclusion, $\%$ & 82 & 75 & 0.02 \\
\hline Duration between $\mathrm{SpA}$ diagnosis and inclusion, days & 272 & 226 & 0.4 \\
\hline Age at IBP onset, yrs & 31.9 & 32.4 & 0.5 \\
\hline \multicolumn{4}{|l|}{ Associated conditions at inclusion } \\
\hline Reactive arthritis, \% & 1.9 & 0.26 & 0.006 \\
\hline SAPHO syndrome, $\%$ & 6 & 2.6 & 0.02 \\
\hline Inflammatory bowel disease, $\%$ & 5.9 & 2.3 & 0.05 \\
\hline \multicolumn{4}{|l|}{ Activity, quality of life } \\
\hline Patient-acceptable symptom state, $\%$ & 37 & 45 & 0.04 \\
\hline BAS-G $(0-10)$ & $5.40 \pm 2.59$ & $4.84 \pm 2.51$ & 0.005 \\
\hline BASDAI (0-100) & $47.4 \pm 20.2$ & $42.4 \pm 18.5$ & 0.001 \\
\hline ASDAS-CRP & $2.63 \pm 1.09$ & $2.39 \pm 0.97$ & 0.003 \\
\hline BASFI $(0-100)$ & $33.5 \pm 23.3$ & $27.9 \pm 21.9$ & 0.001 \\
\hline \multicolumn{4}{|l|}{ Short Form-36 } \\
\hline Physical & $38.64 \pm 8.95$ & $41.04 \pm 9.45$ & 0.001 \\
\hline Mental & $38.93 \pm 11.24$ & $41.30 \pm 11.15$ & 0.005 \\
\hline Health Assessment Questionnaire (0-3) & $0.66 \pm 0.52$ & $0.54 \pm 0.49$ & 0.001 \\
\hline ASQoL & $10.11 \pm 4.71$ & $8.57 \pm 5.07$ & 0.001 \\
\hline \multicolumn{4}{|l|}{ Clinical findings } \\
\hline Enthesis index $(0-13)$ & $3.65 \pm 3.57$ & $1.91 \pm 2.53$ & 0.001 \\
\hline Articular index & $5.84 \pm 10.05$ & $3.04 \pm 6.82$ & 0.001 \\
\hline BASMI (0-10) & $2.47 \pm 1.04$ & $2.32 \pm 0.97$ & 0.04 \\
\hline \multicolumn{4}{|l|}{ Laboratory tests } \\
\hline HLA-B27, \% & 61 & 55 & 0.15 \\
\hline $\mathrm{CRP}, \mathrm{mg} / \mathrm{l}$ & $10.3 \pm 16.8$ & $7.8 \pm 12.0$ & 0.02 \\
\hline Hemoglobin, $\mathrm{g} / \mathrm{dl}$ & $15.3 \pm 18.8$ & $16.1 \pm 17.4$ & 0.05 \\
\hline \multicolumn{4}{|l|}{ Imaging } \\
\hline Radiographic sacroiliitis*, $\%$ & 54 & 45 & 0.003 \\
\hline mSASSS & $1.17 \pm 3.11$ & $1.0 \pm 2.7$ & 0.3 \\
\hline
\end{tabular}

\footnotetext{
* Score $\geq 1$ (see text for details). CRP: C-reactive protein; BASDAI: Bath Ankylosing Spondylitis Disease Activity Index; ASDAS-CRP: Ankylosing Spondylitis Disease Activity Score (CRP based); BASFI: Bath Ankylosing Spondylitis Functional Index; BASMI: Bath Ankylosing Spondylitis Metrology Index; mSASSS: modified Stoke Ankylosing Spondylitis Spinal Score; IBP: inflammatory back pain; ASQoL: Ankylosing Spondylitis Quality of Life questionnaire; BAS-G: Bath Ankylosing Spondylitis Global Score; ASAS: Assessment of Spondyloarthritis International Society; ESSG: European Spondyloarthropathy Study Group; SpA: spondyloarthritis; SAPHO: synovitis, acne, pustolosis, hyperostosis, osteitis.
}

with early $\mathrm{SpA}$ evaluated by Ramonda, et $a l^{11}, 36 \%$ complained of pain and/or tenderness of ACW. In the study by Weber, et $a l^{12}$ of $122 \mathrm{SpA}$ patients, ACW pain or tenderness was present in $26 \%$.

ACW pain occurred before IBP and represented the first rheumatologic symptom of SpA in $14 \%$ of patients with $\mathrm{ACW}$ pain and $6 \%$ of the whole cohort; this can be compared with $9.8 \%$ of patients with ACW pain and 3.6\% of the whole cohort (with mean delay before diagnosis of
4.2 years) in the series from Elhai, et $a l^{4}$. Elhai, et $a l^{4}$ demonstrated a clear relationship of chest pain with duration of the disease.

In our cohort, $\mathrm{ACW}$ pain was distributed between several localizations of the ACW, diffuse in $41 \%$ of the positive cases, sternocostal in $35 \%$, manubriosternal in $29 \%$, or sternoclavicular in $26 \%$, with the possibility of several simultaneous localizations. In the Cochin experience ${ }^{4}$, the joints involved were sternocostal joints $>60 \%$, manubrio- 
Table 2. Stepwise multivariate analysis (the item "diagnosis of ankylosing spondylitis before inclusion in the study" not included in the analysis, because of its relationship with radiological sacroiliitis): significant results.

\begin{tabular}{|c|c|c|c|c|}
\hline & $\begin{array}{l}\text { ACW Pain } \\
\mathrm{n}=316\end{array}$ & $\begin{array}{c}\text { No ACW Pain, } \\
n=392\end{array}$ & $\begin{array}{l}\text { Adjusted OR } \\
\quad(95 \% \mathrm{CI})\end{array}$ & $\mathrm{p}$ \\
\hline Global enthesitis score $(0-13)$ & $3.65 \pm 3.57$ & $1.91 \pm 2.53$ & \multicolumn{2}{|c|}{ For an increase of 1 unit } \\
\hline $\begin{array}{l}\text { Involvement of thoracic spine (pain), } \\
\text { yes vs no (\%) }\end{array}$ & $212(67)$ & $192(49)$ & $2.204(1.590-3.054)$ & $<0.0001$ \\
\hline \multicolumn{5}{|l|}{ Radiographic sacroiliac score $(\%)$} \\
\hline 0 : normal & $142(46)$ & $209(55)$ & & \\
\hline 1: doubtful & $81(26)$ & $75(20)$ & $1.7474(1.168-2.611)$ & 0.0066 \\
\hline 2: established or fusion & $88(27.9)$ & $99(25.78)$ & $1.648(0.122-2.420)$ & 0.0108 \\
\hline
\end{tabular}

ACW: anterior chest wall.

sternal $48 \%$, and sternoclavicular joint $33 \%$. In the series from Fournié, et $a l^{2}$, in 50 patients with AS and 50 with psoriatic arthritis, ACW involvement was found in half the patients, the most common sites being manubriosternal symphysis and sternoclavicular joints. In the study from Ramonda, et $a l^{11}$, at clinical examination, sternocostoclavicular joints were involved in about $80 \%$ of the cases and the sternum in $35 \%$.

Our results clearly suggest ACW involvement as a marker of disease activity and severity. Patients with ACW pain showed lower percentage of patient-acceptable symptom state, increased disease activity (BAS-G, BASDAI, ASDAS, CRP), and reduced functional capacities and quality of life (increased BASFI, BASMI, HAQ scores, reduced SF-36 physical and mental component scores); all were statistically significantly different from patients without ACW pain. This was noted by Dawes, et al ${ }^{10}$, who found significantly longer duration of morning stiffness and reduced spinal mobility in AS patients with chest pain compared to those without. In contrast, Elhai, et al reported that patients with ACW pain in established SpA did not have more severe disease ${ }^{4}$, without giving more details.

ACW pain was associated in our population with thoracic spine and peripheral involvement (joint scores and enthesitis scores), but not with dactylitis. This was not the case in the study from Elhai, et $a l^{4}$ in established SpA, which found an association only between ACW pain and heel pain. In univariate analysis in our study, an association was found with reactive arthritis and SAPHO syndrome (and a trend to association with IBD), but not with psoriasis or uveitis. In multivariate analysis, the relation with enthesitis remained significant.

ACW pain was associated with fulfillment of the ASAS and ESSG criteria and with diagnosis of AS in the univariate analysis, and with radiographic sacroiliitis in the univariate and multivariate analyses. Diagnosis of AS was more frequent in patients with chest pain in the study by Elhai, et $a l^{4}$; in a 10 -year retrospective study of 268 patients with seronegative arthritis, radiographic ACW involvement was significantly related in the AS patients to advanced sacroiliitis and spine involvement (and disease duration) ${ }^{3}$; and ACW lesions found by MRI occurred more frequently in AS patients than in those with nonradiographic SpA, out of 122 patients with $\mathrm{SpA}^{12}$.

Specific imaging procedures for ACW involvement were not planned as part of the protocol of the DESIR cohort, and this represents the main limitation of our study. Some data on this are available in the literature. $\mathrm{Jurik}^{3}$ found radiographic involvement of the sternoclavicular joint in $17 \%$ and of the manubriosternal joint in $51 \%$ of patients with AS studied. In the 110 patients with early SpA described by Ramonda, et al $^{11}$, a bone scan was positive in $100 \%$ and an MRI scan in $62.5 \%$ of those with clinical involvement. Weber, et $a l^{12}$ assessed whole-body MRI in 122 patients with $\mathrm{SpA}$ (95 AS, median disease duration 11 yrs; and 27 nonradiographic SpA, median disease duration $1.2 \mathrm{yrs}$ ) and 75 healthy controls. Bone marrow edema was recorded in $44.3 \%$ of patients with $\mathrm{SpA}$, in $25 \%$ of the patients with IBP, and in $9.3 \%$ of controls. That study demonstrated the lack of association between clinical and imaging findings indicative of inflammation in ACW involvement in SpA: the agreement between patient self-report of pain and ACW tenderness on clinical examination was moderate (kappa value 0.5); kappa values between clinical and MRI inflammation ranged from -0.18 to 0.25 for all patients with SpA.

Together, our results confirm the high prevalence of ACW pain in early SpA. ACW pain in these patients with recent IBP suggestive of SpA was associated with higher disease activity and severity, and with higher rates of radiographic changes of SI joints and diagnosis of AS. This association was not related to a longer duration of symptoms (because age and symptom duration were similar in patients with and those without ACW pain), so ACW pain might be regarded as a diagnostic (classification) feature of axial SpA.

\section{ACKNOWLEDGMENT}

We thank all the investigators and teams involved in the DESIR cohort.

Personal non-commercial use only. The Journal of Rheumatology Copyright $\odot$ 2013. All rights reserved. 


\section{REFERENCES}

1. Rudwaleit M, Taylor WJ. Classification criteria for psoriatic arthritis and ankylosing spondylitis/axial spondyloarthritis. Best Pract Res Clin Rheumatol 2010;24:589-604.

2. Fournié B, Boutes A, Dromer C, Sixou L, Le Guennec P, Granel J, et al. Prospective study of anterior chest wall involvement in ankylosing spondylitis and psoriatic arthritis. Rev Rhum Engl Ed 1997;64:22-5.

3. Jurik AG. Anterior chest wall involvement in seronegative arthritides. A study of the frequency of changes at radiography. Rheumatol Int 1992;12:7-11.

4. Elhai M, Paternotte S, Burki V, Durnez A, Fabrequet I, Koumakis $\mathrm{E}$, et al. Clinical characteristics of anterior chest wall pain in spondyloarthritis: an analysis of 275 patients. Joint Bone Spine 2012;79:476-81.

5. Calin A, Porta J, Fries JF, Schurman DJ. Clinical history as a screening test for ankylosing spondylitis. JAMA 1977;237:2613-4.

6. Rudwaleit M, Metter A, Listing J, Sieper J, Braun J. Inflammatory back pain in ankylosing spondylitis: A reassessment of the clinical history for application as classification and diagnostic criteria. Arthritis Rheum 2006;54:569-78.

7. Dougados M, d'Agostino MA, Benessiano J, Berenbaum F, Breban M, Claudepierre P, et al. The DESIR cohort: A 10-year follow-up of early inflammatory back pain in France: study design and baseline characteristics of the 708 recruited patients. Joint Bone Spine 2011;78:598-603.

8. van der Heijde D, Lie E, Kvien TK, Sieper J, van den Bosch F, Listing J, et al. ASDAS, a highly discriminatory ASAS-endorsed disease activity score in patients with ankylosing spondylitis. Ann Rheum Dis 2009;68:1811-8.

9. Creemers M, Franssen MJ, van 't Hof MA, Gribnau FW, van de Putte LB, van Riel PL. Assessment of outcome in ankylosing spondylitis: an extended radiographic scoring system. Ann Rheum Dis 2004;64:127-9.

10. Dawes PT, Sheeran TP, Hothersall TE. Chest pain - a common feature of ankylosing spondylitis. Postgrad Med J 1988;64:27-9.

11. Ramonda R, Lorenzin M, Lo Nigro A, Vio S, Zucchetta P, Frallonardo $\mathrm{P}$, et al. Anterior chest wall involvement in early stages of spondyloarthritis: advanced diagnostic tools. J Rheumatol 2012;39:1844-9.

12. Weber U, Lambert RG, Rufibach K, Maksymowych WP, Hodler J, Zejden A, et al. Anterior chest wall inflammation by whole-body magnetic resonance imaging in patients with spondyloarthritis: Lack of association between clinical and imaging findings in a cross-sectional study. Arthritis Res Ther 2012;14:R3. 